\title{
BMJ Open Grip strength among Indigenous and non-Indigenous Australian adults: a longitudinal study of the effects of birth size and current size
}

Timothy Howarth, ${ }^{1}$ Belinda Davison, ${ }^{2}$ Gurmeet Singh ${ }^{2}$

To cite: Howarth T, Davison B, Singh G. Grip strength among Indigenous and non-Indigenous Australian adults: a longitudinal study of the effects of birth size and current size. BMJ Open 2019;9:e024749. doi:10.1136/ bmjopen-2018-024749

- Prepublication history for this paper is available online. To view these files, please visit the journal online (http://dx.doi. org/10.1136/bmjopen-2018024749).

Received 11 July 2018 Revised 8 February 2019 Accepted 12 February 2019
Check for updates

(C) Author(s) (or their employer(s)) 2019. Re-use permitted under CC BY-NC. No commercial re-use. See rights and permissions. Published by BMJ.

${ }^{1}$ Child Health, Menzies School of Health Research, Casuarina Northern Territory, Australia ${ }^{2}$ Child Health, Menzies School of Heath Research, Institute of Advanced Studies, Charles Darwin University, Darwin, Northern Territory, Australia

Correspondence to Dr Belinda Davison; belinda.davison@menzies. edu.au

\section{ABSTRACT}

Objectives Indigenous Australians are born smaller than non-Indigenous Australians and are at an increased risk of early onset of frailty. This study aimed to identify the relationship between birth size, current size and grip strength, as an early marker of frailty, in Indigenous and non-Indigenous young adults.

Design Cross sectional data from two longitudinal studies: Aboriginal birth cohort (Indigenous) and top end cohort (non-Indigenous).

Setting Participants reside in over 40 urban and remote communities across the Northern Territory, Australia.

Participants Young adults with median age 25 years (IQR 24-26); 427 participants (55\% women), 267 (63\%) were remote Indigenous, 55 (13\%) urban Indigenous and 105 (25\%) urban non-Indigenous.

Outcome measures Reliable birth data were available. Anthropometric data (height, weight, lean mass) and grip strength were directly collected using standardised methods. Current residence was classified as urban or remote.

Results The rate of low birthweight (LBW) in the nonIndigenous cohort (9\%) was significantly lower than the Indigenous cohort (16\%) $(-7 \%, 95 \% \mathrm{Cl}-14$ to 0 , $\mathrm{p}=0.03$ ). Indigenous participants had lower grip strength than non-Indigenous (women, $-2.08,95 \% \mathrm{Cl}-3.61$ to $-0.55, \mathrm{p}=0.008$ and men, $-6.2,95 \% \mathrm{Cl}-9.84$ to -2.46 , $\mathrm{p}=0.001$ ). Birth weight (BW) was associated with grip strength after adjusting for demographic factors for both women $(\beta=1.29,95 \% \mathrm{Cl} 0.41$ to $2.16, p=0.004)$ and men $(\beta=3.95,95 \% \mathrm{Cl} 2.38$ to $5.51, p<0.001)$. When current size (lean mass and body mass index [BMI]) was introduced to the model BW was no longer a significant factor. Lean mass was a positive indicator for grip strength, and BMl a negative indicator.

Conclusions As expected women had significantly lower grip strength than men. Current size, in particular lean mass, was the strongest predictor of adult grip strength in this cohort. BW may have an indirect effect on later grip strength via moderation of lean mass development, especially through adolescence and young adulthood.

\section{INTRODUCTION}

Grip strength in adulthood is a measure of muscle strength in the arm and a marker of future morbidity and mortality. ${ }^{1-5}$ Lowered
Strengths and limitations of this study

Directly collected data, including detailed body composition, using standardised methods.

- Inclusion of previously understudied, remote and very remote Indigenous Australians.

- Information available in an under-reported, transitional age group; young adulthood.

- Limited physical activity data available.

- Limited participant numbers when stratified by gender, indigeneity and location.

grip strength in the elderly has been associated with a decrease in perceived quality of life, ${ }^{4}$ daily functionality, ${ }^{6}$ increased frailty ${ }^{57}$ and heightened risk of all-cause mortality. ${ }^{8} \mathrm{~A}$ large prospective cohort study has linked grip strength in adolescence to increased risk of cardiovascular disease, cancer and poor mental health outcomes, including suicide in early adulthood. ${ }^{9}$

Muscle strength in adulthood is influenced by gender, skeletal size, lean mass and physical activity. ${ }^{10-12}$ Previous research has indicated the divergence in grip strength between genders to be predominantly explained by the differential growth, particularly of muscle mass, through adolescence. ${ }^{13}$ In addition to these factors, several epidemiological studies have drawn associations between birth weight (BW) (as a surrogate for intrauterine growth), ${ }^{7} 1415$ early growth $^{16} 17$ and later grip strength, independent of later size or physical activity. However, the majority of these studies have analysed grip outcomes in mid to late adulthood, and thus it is uncertain if BW leads to reduced peak strength occurring in early adulthood, or a faster decline in grip strength occurring thereafter. Fetal growth restriction, defined as babies in the 10th percentile for gestational age (GA), has 
been shown to have significant influences on muscle metabolism and growth through childhood and into adulthood. ${ }^{18-20}$

Indigenous Australians have significantly higher rates of low birthweight (LBW) babies, ${ }^{21}$ lower life expectancies than non-Indigenous Australians, ${ }^{22}$ and they appear to become frail at an earlier age. ${ }^{23}$ Populations in Australia living rural or remote do not have the same healthcare access, nutritional, educational or employment opportunities as comparable urban populations. ${ }^{224}$ These populations have high mortality rates and lower life expectancies, the lowest of which is found in remote Northern Territory (NT). ${ }^{24}$ Of the 69000 Indigenous people residing in the NT approximately four out of five live in remote/very remote communities and outstations according to Australian geographic standard classification. ${ }^{25}$ Indigenous Australians face many challenges across the life course which may exacerbate the influence of low BW on later health outcomes compared with a non-Indigenous population. Furthermore, the challenges associated with remote or rural living may further exacerbate the effects of low BW.

This study examines the associations of birth size, current size and grip strength in remote Indigenous, urban Indigenous and urban non-Indigenous young adults in the NT.

\section{METHODS}

\section{Participants}

Data are presented from two distinct but complementary longitudinal cohorts based in Darwin, NT: the Aboriginal Birth Cohort $(\mathrm{ABC})$ and the non-Indigenous Top End Cohort (TEC).

The recruitment of the $\mathrm{ABC}$ has been described in detail elsewhere ${ }^{26}$ In brief, the $\mathrm{ABC}$ is a prospective study of 686 babies born to Indigenous mothers (a representative sample of the 1238 eligible babies) recruited at Royal Darwin Hospital (RDH) between January 1987 and March 1990 to a mother recorded as Indigenous in the Delivery Suite Register. RDH is the main hospital for an area covering $120000 \mathrm{~km}^{2}$ of the 'Top End' of the NT and, at the time, $>90 \%$ of pregnant Indigenous mothers from this region came to the RDH to deliver their babies. ${ }^{27}$ The TEC comprises 196 non-Indigenous participants recruited and assessed between 2007 and 2009 (average age 18.3 years). Eligibility criteria were birth in Darwin to a non-Indigenous mother between 1987 and 1991 (ie, age matched to the $\mathrm{ABC}$ ) and still living in Darwin at the time of recruitment. ${ }^{28}$

A combined follow-up of ABC and TEC participants occurred between 2013 and 2015 at a mean age of 23.8 years. Indigenous participants reside in over 40 urban and remote communities across the NT. Remote communities vary in population size from 200 to 2000 people, with many small family groups living in outstations $(<50$ people).

\section{Data collection}

Birth data, including BW and GA, was recorded at recruitment for $\mathrm{ABC}$ participants, and extracted from hospital records for TEC participants. Face-to-face assessments of participants were conducted by trained researchers between 2015 and 2016. Grip strength was assessed using a hand-held dynamometer (Smedley, S dynamometer, TTM, Tokyo, $100 \mathrm{~kg}$ ) following a standardised protocol and recorded in kilograms. Participants had a maximum of three attempts for left and right hands, alternating between trials, with the maximal value, irrespective of hand, used in the analyses.

Anthropometric measures were taken with participants in light clothing and barefoot. Height was recorded on hard, flat flooring to the nearest millimetre using a portable stadiometer. Weight was measured to the nearest $0.1 \mathrm{~kg}$ with a digital electronic scale (TBF-521, Tanita Corporation, Illinois, USA) and lean mass to the nearest $0.1 \mathrm{~kg}$ through bioimpedance measure from the same scale. Body mass index (BMI) was calculated using the standard formula $\left(\mathrm{kg} / \mathrm{m}^{2}\right)$. Physical activity was self-reported and categorised as either active ( $\geq 5$ hours physical activity/week) or inactive ( $<5$ hours physical activity/ week).

\section{Statistical analyses}

Statistical analysis was performed in STATA 14.2 (College Station, TX). Participants were included if they had complete data (including at least two recorded grip strength attempts from the same hand). Residence was classified as living 'remote' (remote community with an Aboriginal council) or 'urban' (Darwin \& rural towns) at the date of collection. Quantile regression was used to determine differences between medians for GA, linear regression to determine differences between means for BW, height, weight, lean mass and BMI, and proportions test to determine difference in proportion engaging in physical activity. Each test was stratified by gender, Indigenous status and location. Univariate linear regression was used to explore the relationship between grip strength, gender, Indigenous status and location. Multivariate regression adjusted the effect of birth size and current size for gender, Indigenous status and location. Continuous variables for multivariate regressions were standardised among women and men respectively, and coefficients reported as SD increases.

\section{Participant involvement}

Participants were involved in the development of methods related to this study by cohort reference groups. Results of this study are to be disseminated to the participants via private Facebook groups of both cohorts, and on the study website.

\section{RESULTS}

Of the 576 participants seen (55\% women), 89 (16\%) were excluded due to having no $(n=88)$ or only a single 
Table 1 Descriptive overview of cohort characteristics

\begin{tabular}{|c|c|c|c|}
\hline & Remote Indigenous & Urban Indigenous & Urban non-Indigenous \\
\hline Women & $n=145$ & $\mathrm{n}=24$ & $\mathrm{n}=66$ \\
\hline Gestational age (weeks, IQR) & $39(39,40)$ & $39(38,39)$ & $40(40,40)$ \\
\hline Age (years) & $25.1(24.9-25.3)$ & $25.2(24.7-25.7)$ & 23.6 (23.2-23.9) \\
\hline Height (cm) & $161.7(160.8-162.6)$ & $162.1(159.9-164.2)$ & $166.4(164.6-168.3)$ \\
\hline Lean mass (kg) & $41.4(40.5-42.3)$ & $43.8(42.1-45.6)$ & 45.7 (44.5-46.9) \\
\hline Body mass index $\left(\mathrm{kg} / \mathrm{m}^{2}\right)$ & $24.2(23.1-25.3)$ & $26.5(24.2-28.8)$ & $23.7(22.5-24.9)$ \\
\hline Physical activity (\%) & $37.23(29.3-48.8)$ & $29.2(9.6-48.8)$ & $60.6(48.5-72.7)$ \\
\hline Grip strength (kg) & $21(20.1-22)$ & $20.5(18.5-22.4)$ & $23.2(21.8-24.7)$ \\
\hline Men & $n=122$ & $\mathrm{n}=31$ & $n=39$ \\
\hline Age (years) & $25.4(25.2-25.6)$ & $25.5(25-25.9)$ & $24.1(23.6-24.6)$ \\
\hline Height (cm) & $173.6(172.3-174.8)$ & $177.2(174.2-180.1)$ & $179.9(176.5-183.2)$ \\
\hline Weight (kg) & $68(64.7-71.2)$ & 89.6 (79.5-99.6) & 82.6 (77.9-87.3) \\
\hline Lean mass (kg) & $54.4(52.7-56)$ & $64.4(60.3-68.5)$ & $65.3(62.4-68.1)$ \\
\hline Body mass index $\left(\mathrm{kg} / \mathrm{m}^{2}\right)$ & $22.5(21.5-23.4)$ & $28.2(25.6-30.9)$ & $25.5(24.2-26.9)$ \\
\hline Physical activity (\%) & $82(75.1-88.9)$ & $58.1(39.7-76.5)$ & $66.7(51.2-82.1)$ \\
\hline Grip strength (kg) & $36.7(35-38.4)$ & $47.3(43.4-51.3)$ & $45(42.1-47.8)$ \\
\hline
\end{tabular}

$(\mathrm{n}=1)$ grip strength value recorded, 53 (9\%) had no lean mass measure and $7(1 \%)$ had no GA recorded. Complete data were available on 427 participants, the majority were remote residing Indigenous 267 (63\%), with the remainder urban Indigenous 55 (13\%) and urban non-Indigenous 105 (25\%), reflective of the available cohort (table 1). Median age was 25 years (IQR 24-26).

\section{Birth size}

Indigenous participants were born earlier ( -0.9 weeks, $95 \% \mathrm{CI}-1.16$ to $-0.64, \mathrm{p}<0.001)$ and smaller $(-261.62 \mathrm{~g}$, $95 \%$ CI -385.33 to $-137.9, \mathrm{p}<0.001)$ than non-Indigenous, with $15.5 \%$ born $<2500 \mathrm{~g}$ compared with $8.6 \%$ of non-Indigenous participants $(-7 \%, 95 \%$ CI -13.6 to $-0.2, p=0.0364)$. On stratifying by gender, this significant difference remained for women ( -0.9 weeks, 95\% CI -1.26 to $-0.54, \mathrm{p}<0.001$ and $-338.99 \mathrm{~g}, 95 \%$ CI -490.1 to $-187.89, \mathrm{p}<0.001)$, with Indigenous men born earlier than non-Indigenous men $(-0.9$ weeks, 95\% CI -1.34 to $-0.46, \mathrm{p}<0.001)$ but no significant difference in $\mathrm{BW}$ evident $(-181.9 \mathrm{~g}, 95 \% \mathrm{CI}-389.7$ to $25.9, \mathrm{p}=0.085)$. No differences in birth characteristics were seen between remote and urban residing Indigenous men, however, remote residing Indigenous women were born significantly later $(0.8$ weeks, $95 \%$ CI 0.1 to $1.5, \mathrm{p}=0.025)$ and larger $(295.47 \mathrm{~g}, 95 \%$ CI 59.29 to $531.65, \mathrm{p}=0.015)$ than urban Indigenous women.

\section{Current size}

Indigenous participants were significantly shorter $(-3.73 \mathrm{~cm}, 95 \% \mathrm{CI}-5.82$ to $-1.64, \mathrm{p}=0.001)$ and had less muscle mass $(-4.28 \mathrm{~kg}, 95 \%$ CI -6.71 to $-1.85, \mathrm{p}=0.001)$ than non-Indigenous participants, however no difference in BMI or the proportion engaging in physical activity was seen. When stratified by gender, Indigenous women were shorter $(-4.7 \mathrm{~cm}, 95 \% \mathrm{CI}-6.44$ to $-2.96, \mathrm{p}<0.001)$ and had less muscle mass $(-3.99 \mathrm{~kg}, 95 \%$ CI -5.44 to $-2.54, \mathrm{p}<0.001)$. Indigenous men were shorter $(-5.59 \mathrm{~cm}$, $95 \%$ CI -8.44 to $-2.75, \mathrm{p}<0.001)$, lighter $(-10.24 \mathrm{~kg}$, $95 \%$ CI -17.62 to $-2.85, \mathrm{p}=0.007)$, had less lean muscle mass $(-8.86 \mathrm{~kg}, 95 \% \mathrm{CI}-12.4$ to $-5.32, \mathrm{p}<0.001)$ and engaged in less physical activity $(-24.5$, 95\% CI -10.7 to $-38.3, \mathrm{p}<0.001)$ than non-Indigenous men. Remote residing Indigenous men were significantly shorter $(-3.59 \mathrm{~cm}, 95 \% \mathrm{CI}-6.47$ to $-0.71, \mathrm{p}=0.015)$, lighter $(-21.62 \mathrm{~kg}, 95 \% \mathrm{CI}-29.75$ to $-13.49, \mathrm{p}<0.001)$, had less lean mass $(-10 \mathrm{~kg}, 95 \% \mathrm{CI}-13.78$ to $-6.22, \mathrm{p}<0.001)$ and a lower BMI $\left(-5.78 \mathrm{~kg} / \mathrm{m}^{2}, 95 \% \mathrm{CI}-8\right.$ to $\left.-3.56, \mathrm{p}<0.001\right)$ than their urban counterparts.

\section{Grip strength}

Indigenous women $(-2.27,95 \% \mathrm{CI}-3.89$ to -0.66 , $\mathrm{p}=0.006)$ and men $(-6.15,95 \% \mathrm{CI}-9.84$ to $-2.46 \mathrm{p}=0.001)$ had significantly lower grip strength than their non-Indigenous counterparts. Among Indigenous men, location was a significant influence, however this was not seen in 
Table 2 Standardised coefficients and $p$ values for factor effects on grip strength

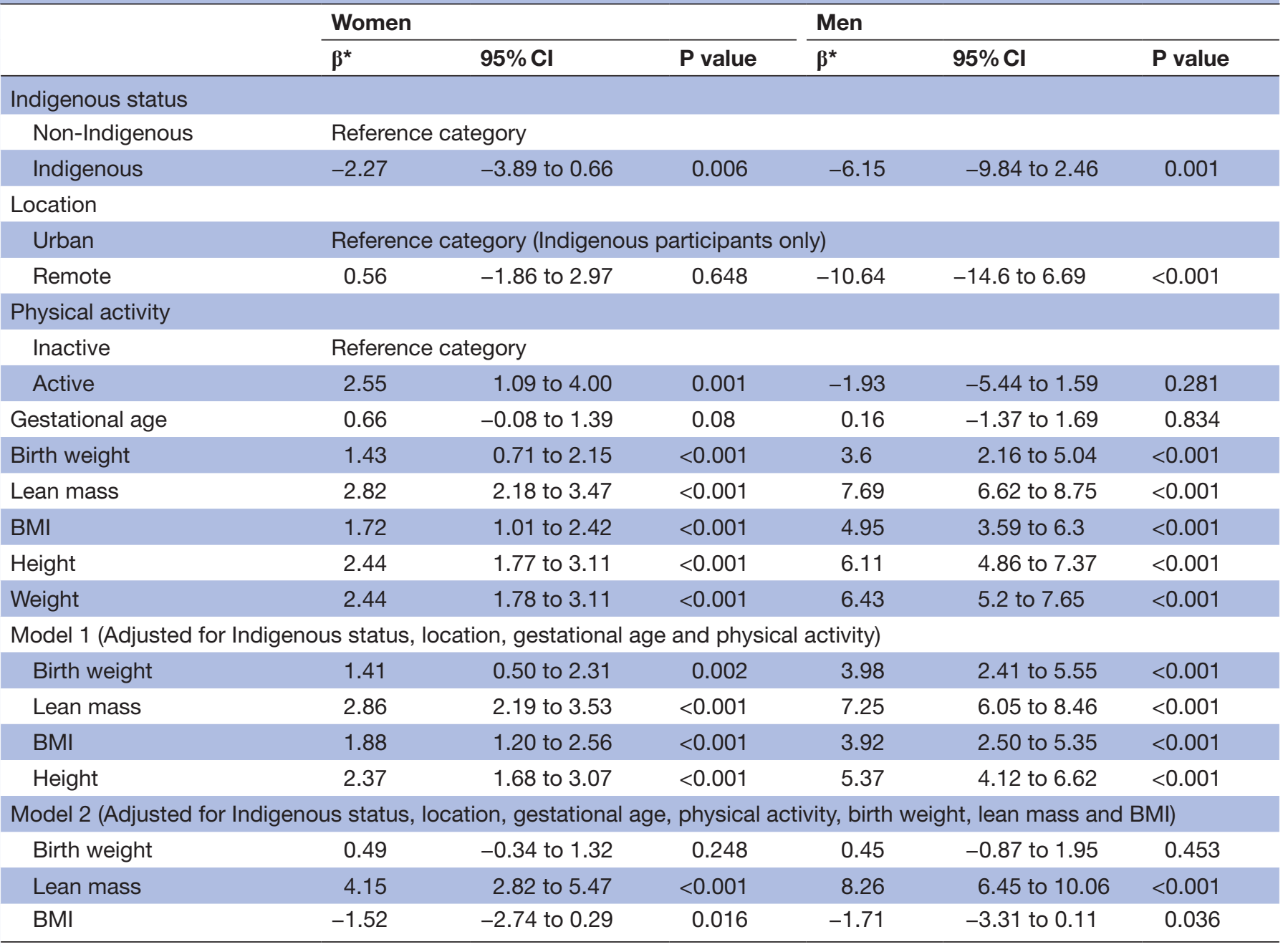

${ }^{*} \beta$ values for continuous variables are standardised such that each unit represents a SD increase.

BMl, body mass index.

women $(0.56,95 \% \mathrm{CI}-1.86$ to $2.97, \mathrm{p}=0.648)$. Remote Indigenous men had a $10.6 \mathrm{~kg}$ deficit $(95 \% \mathrm{CI}-14.6$ to $-6.69, \mathrm{p}<0.001)$ in maximal grip strength compared with urban Indigenous men. Physical activity did not show any association to maximum grip strength (table 2).

\section{Birth size and current size associations with grip strength}

Grip strength was significantly and positively associated with BW in univariate regression and on adjusting for demographic factors and GA in both women and men (table 2). A one SD increase in BW was associated with $1.43 \mathrm{~kg}(95 \%$ CI 0.7 to 2.2$)$ and $3.6 \mathrm{~kg}(95 \%$ CI 2.2 to 5.0$)$ increases in maximum grip strength in women and men respectively (table 2). Current size factors of lean mass, BMI and height were also significantly and positively associated after adjustment, with lean mass having the greatest effect on grip strength.

The influence of BW on grip strength was attenuated in the full model, with further adjustment for current size. Inclusion of BMI as opposed to height showed a slightly stronger model. Among women, lean mass, BMI and physical activity were significant factors, while among men only lean mass and BMI remained significant. The influence of lean mass was significantly stronger in men $(8.3 \mathrm{~kg}, 95 \%$ CI 6.5 to 10.1$)$ compared with women $(4.2 \mathrm{~kg}$ $95 \%$ CI 2.8 to 5.5 ). BMI showed a significant negative association with grip strength in women $(-1.52,95 \% \mathrm{CI}-2.74$ to $-0.29, \mathrm{p}=0.016)$ and men $(-1.71,95 \% \mathrm{CI}-3.31$ to -0.11 , $\mathrm{p}=0.036$ ), with a similar influence between genders.

The full model accounted for $32 \%$ and $54.8 \%$ of variation for women and men, respectively. Indigenous status and location appeared to have an interactive effect which differed between women and men (figure 1). In comparison to urban non-Indigenous women, remote Indigenous women had greater grip strength. Among men, the urban Indigenous group had greater grip strength.

\section{DISCUSSION}

In this cohort, as expected women displayed significantly lower grip strength than their male peers. Overall, 

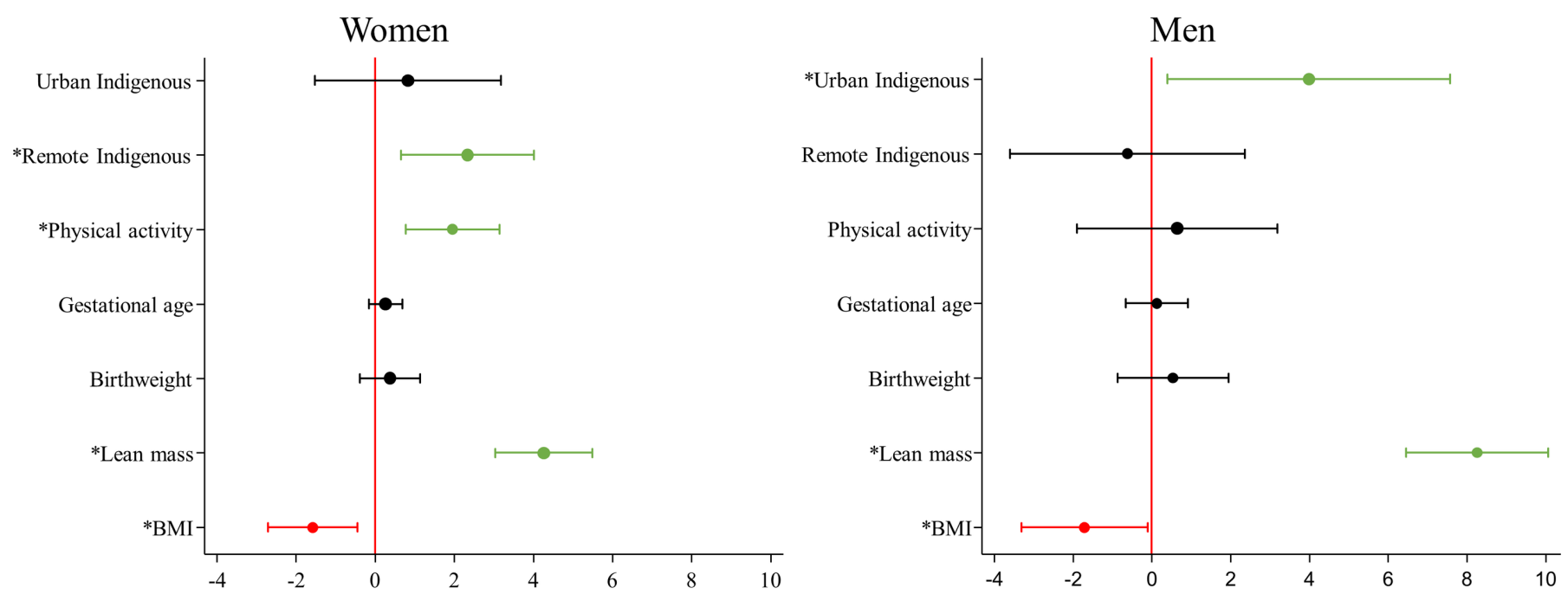

* p-value $\leq 0.05$

Margins for standardized beta coefficients in the multivariate model are displayed. Values to the right of the 0 line indicate standard deviation increases in grip strength for each standard deviation increase in the factor variable. Values to the left indicate standard deviation decreases in grip strength.

Figure 1 Standardised margins of effects on adult grip strength. BMI, body mass index.

Indigenous participants had a lower grip strength than non-Indigenous; however the effect of living remote or urban differed between women and men. Remote Indigenous men recorded lower grip strength than their urban Indigenous peers, while among women there was no significant difference.

The mean grip strength for women, regardless of if remote Indigenous (21.2 kg, 95\% CI 20.34 to 22.1$)$, urban Indigenous $(20.5 \mathrm{~kg}, 95 \% \mathrm{CI} 18.5$ to 22.4$)$ or non-Indigenous $(23.2 \mathrm{~kg}$, 95\% CI 21.8 to 24.7$)$, was significantly lower than reported Australian values for women $(30 \mathrm{~kg}$ $\pm 7 \mathrm{~kg}) .^{29}$ Despite being much younger, women in the current cohort recorded grip strength values similar to those previously recorded for women aged $60-69$ years. ${ }^{29}$ Among men, both urban Indigenous $(47.3 \mathrm{~kg}, 95 \% \mathrm{CI}$ 43.4 to 51.3$)$ and non-Indigenous $(45 \mathrm{~kg}, 95 \% \mathrm{CI} 42.1$ to 47.8) participants displayed similar values to previously reported values for Australian men $(47 \mathrm{~kg} \pm 9.5)$, however remote Indigenous men $(36.7 \mathrm{~kg}, 95 \%$ CI 34.9 to 38.4$)$ were significantly weaker. ${ }^{29}$

Differing grip strength values have been recorded across ethnicities, ${ }^{30} 31$ with Asian countries displaying significantly lower values than western countries. The population in urban Darwin is highly multicultural, with migrants drawn largely from south Asian countries. ${ }^{32}$ In the current study this ethnic ancestry may have led to the lowered grip scores seen in the urban non-Indigenous participants.

Indigenous Australians, especially those living remote, have been described as having characteristics similar to those of populations in developing regions internationally. Factors such as access to food, rates of infection and chronic disease, and lifestyle risk factors such as smoking, alcohol and physical inactivity may have contributed to the lower grip strength seen. ${ }^{33}$ Adedoyin et al reported on grip strength among Nigerian men and women. ${ }^{34}$
Nigerian men aged 20-29 displayed similar maximal grip strength $(39 \mathrm{~kg} \pm 10.9 \mathrm{~kg})$ to the remote residing Indigenous men in this study $(36.7 \mathrm{~kg})$. In the same study, Nigerian women aged 20-29 recorded significantly higher grip strength $(25.1 \mathrm{~kg} \pm 6.4)$ than both remote $(21.3 \mathrm{~kg})$ and urban $(20.5 \mathrm{~kg})$ Indigenous women in the current study. Another study conducted in Malaysia reported grip strength of $17.1 \mathrm{~kg}( \pm 5 \mathrm{~kg})$ and $32.3 \mathrm{~kg}( \pm 7.8 \mathrm{~kg})$ for women and men, respectively. ${ }^{35}$ Differing methodologies and equipment limit comparability between the studies, however it appears grip strength of Indigenous Australian women and remote residing Indigenous men in this cohort is similar to that seen in developing countries.

The gender differences noted for the influence of location are likely due to the difference in muscle fibre composition between women and men. Men typically display a significantly greater proportion of type II muscle fibres than women. ${ }^{36}$ Studies in animal models suggest that type II muscle fibres experience greater burden from food deprivation than type I muscle fibres. ${ }^{378}$ Thus in adverse environments, type II muscular atrophy and resultant strength decline would effect men to a greater degree than women.

Although BW showed significant associations with grip strength in this cohort, it was attenuated after adjusting for current size. Several previous studies have identified such an influence of BW on grip strength, which remained after adjusting for height and weight. ${ }^{163940}$ In previous research, when an adjustment was made for lean mass the association between grip strength and BW disappeared in men, and was significantly attenuated in women. ${ }^{37}$ Furthermore, BW was significantly and positively correlated with adult lean mass. Adolescents born LBW have shown decreased odds of engaging in leisure time physical activity which may be the mechanism of reduced lean mass in adulthood. ${ }^{39}$ However, in the 
current study a separate analysis found non-significantly heightened odds of physical activity among LBW participants. Jensen $e t a t^{41}$ described a decreased proportion of type II muscle fibres in young adults born LBW thereby decreasing their anaerobic capacity, and potentially lower grip strength. ${ }^{40}$

Adult lean mass was a stronger predictor of grip strength than BMI, accounting for $30 \%$ and $50 \%$ of variation in grip strength for women and men, respectively. For both women and men increasing BMI, when adjusted for lean mass, was associated with a decrease in grip strength. In this case, due to the adjustment of lean mass, the increased BMI is a function of increased adiposity, which may be the result of decreased physical activity. Ylihärsilä et $a l^{39}$ described a significant negative association between grip strength and per cent body fat, corroborating this theory. ${ }^{37}$ Individuals who are sedentary have been shown to have lower grip strength compared with active peers, while among the elderly, increased BMI has been associated with decreased grip strength. ${ }^{29} 3442$

Grip dynamometry is a cheap, efficient and reliable test which can be fairly easily incorporated into clinical environments. ${ }^{43}{ }^{44}$ Many participants in this study had grip strength values well below the norm for their age group which is concerning given the associations between grip strength and risk of early sarcopenia, ${ }^{16} 3045$ limited mobility and frailty, ${ }^{46}$ type 2 diabetes, ${ }^{31}$ and premature mortality. It has also been associated with poor mental health outcomes, including suicide. ${ }^{9}$ Early identification in primary healthcare gives the opportunity for early interventions. Young adults respond faster and to a relatively greater degree to exercise interventions than older adults. Furthermore, grip strength may serve as a more visible motivator for lifestyle change compared with triglycerides or glucose levels, and testing can be more palatable allowing for consistent progress checks. The significant influence of location among male participants is a novel result and may warrant further attention for remote healthcare practitioners.

\section{Limitations}

The main limitation of this study is the relatively small participant numbers that may have reduced the power to detect small associations. However, several significant associations were seen. The unequal distribution between remote and urban participants, while affecting the power of results, is representative of the Indigenous population distribution in the NT.

The influence of the interviewer on outcomes has previously been listed as a confounder. ${ }^{416}{ }^{17}$ In a separate analyses introducing an adjustment for the interviewer the difference in this cohort was found to be negligible $(\beta=0.001)$.

\section{CONCLUSION}

Remote Indigenous participants had significantly lower grip strength than their urban peers, which may place them at an increased risk of early morbidity and mortality. Remote Indigenous men displayed the typical antecedents of low grip strength; that is being born small and remaining smaller on all measures of current size. The major difference in strength, birth size and current size between remote and urban young adults, particularly in men, highlights the need for specialised health programmes tailored to region and cultural context.

Acknowledgements We wish to acknowledge past and present study teams, in particular Dr Susan Sayers, founder of the ABC study. We especially thank the young adults belonging to the Aboriginal Birth Cohort and Top End Cohort and their families and community for their cooperation and support and all the individuals who helped in the urban and rural locations.

Contributors GS and BD were involved in the concept and design of the study and acquisition of data, TH was responsible for analyses and interpretation of data and drafted the manuscript, all authors revised article critically for important intellectual content, and provided final approval of the version submitted.

Funding This work was supported by the National Health and Medical Research Council of Australia (Project Grant APP1046391).

Competing interests None declared.

Patient consent for publication Not required.

Ethics approval All participants provided written informed consent to participate in this study, and all procedures were approved by the Human Research Ethics Committee of the Northern Territory Department of Health and the Menzies School of Health Research, including the Aboriginal Ethical Sub-committee which has the power of veto (ABC Reference no. 2013-2022 and TEC Reference no. 2013-1986).

Provenance and peer review Not commissioned; externally peer reviewed.

Data sharing statement All data are stored confidentially and although not freely available in the public domain, is available on request and specific proposals for collaboration are welcomed.

Open access This is an open access article distributed in accordance with the Creative Commons Attribution Non Commercial (CC BY-NC 4.0) license, which permits others to distribute, remix, adapt, build upon this work non-commercially, and license their derivative works on different terms, provided the original work is properly cited, appropriate credit is given, any changes made indicated, and the use is non-commercial. See: http://creativecommons.org/licenses/by-nc/4.0/.

\section{REFERENCES}

1. Laukkanen P, Heikkinen E, Kauppinen M. Muscle strength and mobility as predictors of survival in 75-84-year-old people. Age Ageing 1995;24:468-73.

2. Rantanen T, Harris T, Leveille SG, et al. Muscle strength and body mass index as long-term predictors of mortality in initially healthy men. J Gerontol A Biol Sci Med Sci 2000;55:M168-73.

3. Sayer AA, Syddall H, O'Dell SD, et al. Polymorphism of the IGF2 gene, birth weight and grip strength in adult men. Age Ageing 2002;31:468-70.

4. Sayer AA, Syddall HE, Martin HJ, et al. Is grip strength associated with health-related quality of life? Findings from the Hertfordshire Cohort Study. Age Ageing 2006;35:409-15.

5. Syddall $\mathrm{H}$, Cooper $\mathrm{C}$, Martin $\mathrm{F}$, et al. Is grip strength a useful single marker of frailty? Age Ageing 2003;32:650-6.

6. Ensrud KE, Nevitt MC, Yunis C, et al. Correlates of impaired function in older women. J Am Geriatr Soc 1994;42:481-9.

7. Dodds R, Denison HJ, Ntani G, et al. Birth weight and muscle strength: a systematic review and meta-analysis. J Nutr Health Aging 2012;16:1-7.

8. Strand $\mathrm{BH}$, Cooper R, Bergland A, et al. The association of grip strength from midlife onwards with all-cause and cause-specific mortality over 17 years of follow-up in the Troms $\varnothing$ Study. J Epidemiol Community Health 2016;70:1214-21.

9. Ortega FB, Silventoinen K, Tynelius P, et al. Muscular strength in male adolescents and premature death: cohort study of one million participants. BMJ 2012;345:e7279.

10. Davies MJ, Dalsky GP. Normalizing strength for body size differences in older adults. Med Sci Sports Exerc 1997;29:713-7. 
11. Reed RL, Pearlmutter L, Yochum K, et al. The relationship between muscle mass and muscle strength in the elderly. J Am Geriatr Soc 1991;39:555-61.

12. Patel HP, Jameson KA, Syddall HE, et al. Developmental influences, muscle morphology, and sarcopenia in community-dwelling older men. J Gerontol A Biol Sci Med Sci 2012;67:glr020.

13. Sartorio A, Lafortuna CL, Pogliaghi $S$, et al. The impact of gender, body dimension and body composition on hand-grip strength in healthy children. J Endocrinol Invest 2002;25:431-5.

14. Gale CR, Martyn CN, Kellingray S, et al. Intrauterine programming of adult body composition. J Clin Endocrinol Metab 2001;86:267-72.

15. Kahn HS, Narayan KM, Williamson DF, et al. Relation of birth weight to lean and fat thigh tissue in young men. Int $J$ Obes Relat Metab Disord 2000;24:667-72.

16. Kuh D, Bassey J, Hardy R, et al. Birth weight, childhood size, and muscle strength in adult life: evidence from a birth cohort study. Am $J$ Epidemiol 2002;156:627-33.

17. Kuh D, Hardy R, Butterworth S, et al. Developmental origins of midlife grip strength: findings from a birth cohort study. J Gerontol A Biol Sci Med Sci 2006;61:702-6.

18. Singhal A, Wells J, Cole TJ, et al. Programming of lean body mass: a link between birth weight, obesity, and cardiovascular disease? Am J Clin Nutr 2003;77:726-30.

19. Lapillonne A, Braillon P, Claris O, et al. Body composition in appropriate and in small for gestational age infants. Acta Paediatr 1997;86:196-200.

20. Hediger ML, Overpeck MD, Kuczmarski RJ, et al. Muscularity and fatness of infants and young children born small- or large-forgestational-age. Pediatrics 1998;102:e60.

21. Australian Institute of Health and Welfare. Birthweight of babies born to Indigenous Mothers: AlHW, 2014.

22. Australian Indigenous HealthInfoNet. Summary of Aboriginal and Torres Strait Islander health 2017. Perth, WA: Australian Indigenous HealthInfoNet. 2016;225:3.

23. Hyde Z, Flicker L, Smith K, et al. Prevalence and incidence of frailty in Aboriginal Australians, and associations with mortality and disability. Maturitas 2016;87:89-94.

24. Phillips A. Health status differentials across rural and remote Australia. Aust J Rural Health 2009;17:2-9.

25. Australian Bureau of Statistics. Estimates of Aboriginal and Torres Strait Islander Australians, States and territories, Remoteness Areas(5-year age groups to 75 and over) 2016 (cat no. 3238.0.55.001). Canberra: ABS, 2011.

26. Sayers SM, Mackerras D, Singh GR. Cohort Profile: The Australian Aboriginal Birth Cohort (ABC) study. Int J Epidemiol 2017;46:dyw291.

27. Sayers SM, Powers JR. Birth size of Australian aboriginal babies. Med J Aust 1993;159:586-91.

28. Davison B, Cunningham T, Singh G. Engaging adolescents and young adults in a longitudinal health study: experience from the Top End cohort. Aust N Z J Public Health 2011;35:86-7.

29. Massy-Westropp NM, Gill TK, Taylor AW, et al. Hand Grip Strength: age and gender stratified normative data in a population-based study. BMC Res Notes 2011;4:127.
30. Dodds RM, Syddall HE, Cooper R, et al. Global variation in grip strength: a systematic review and meta-analysis of normative data. Age Ageing 2016;45:209-16.

31. van der Kooi AL, Snijder MB, Peters RJ, et al. The Association of Handgrip Strength and Type 2 Diabetes Mellitus in Six Ethnic Groups: An Analysis of the HELIUS Study. PLoS One 2015;10:e0137739.

32. Australian Bureau of Statistics. Census of Population and Housing (cat no. 2071.0). Canberra: ABS, 2016.

33. Sternäng $O$, Reynolds CA, Finkel D, et al. Factors associated with grip strength decline in older adults. Age Ageing 2015;44:269-74.

34. Adedoyin RA, Ogundapo FA, Mbada CE, et al. Reference Values for Handgrip Strength Among Healthy Adults in Nigeria. Hong Kong Physiotherapy Journal 2009;27:21-9.

35. Kamarul T, Ahmad TS, Loh WY. Hand grip strength in the adult Malaysian population. J Orthop Surg 2006;14:172-7.

36. Staron RS, Hagerman FC, Hikida RS, et al. Fiber type composition of the vastus lateralis muscle of young men and women. J Histochem Cytochem 2000;48:623-9.

37. Matsakas A, Patel K. Skeletal muscle fibre plasticity in response to selected environmental and physiological stimuli. Histol Histopathol 2009;24:611-29.

38. Goodman CA, Kotecki JA, Jacobs BL, et al. Muscle fiber typedependent differences in the regulation of protein synthesis. PLoS One 2012;7:e37890.

39. Ylihärsilä H, Kajantie E, Osmond C, et al. Birth size, adult body composition and muscle strength in later life. Int $J$ Obes 2007;31:1392-9.

40. Bielemann RM, Gigante DP, Horta BL. Birth weight, intrauterine growth restriction and nutritional status in childhood in relation to grip strength in adults: from the 1982 Pelotas (Brazil) birth cohort. Nutrition 2016;32:228-35.

41. Jensen CB, Storgaard H, Madsbad S, et al. Altered skeletal muscle fiber composition and size precede whole-body insulin resistance in young men with low birth weight. J Clin Endocrinol Metab 2007;92:1530-4.

42. Aadahl M, Beyer N, Linneberg A, et al. Grip strength and lower limb extension power in 19-72-year-old Danish men and women: the Health2006 study. BMJ Open 2011;1:e000192.

43. May CR, Patel HP, Patel HP, et al. Implementation of grip strength measurement in medicine for older people wards as part of routine admission assessment: identifying facilitators and barriers using a theory-led intervention. BMC Geriatr 2018;18:79.

44. Denison HJ, Martin HJ, Martin HJ, et al. A review of the measurement of grip strength in clinical and epidemiological studies: towards a standardised approach. Age Ageing 2011;40:423-9.

45. Bahat G, Tufan A, Tufan F, et al. Cut-off points to identify sarcopenia according to European Working Group on Sarcopenia in Older People (EWGSOP) definition. Clin Nutr 2016;35:1557-63.

46. Sallinen J, Stenholm S, Rantanen T, et al. Hand-grip strength cut points to screen older persons at risk for mobility limitation. J Am Geriatr Soc 2010;58:1721-6. 